\title{
Human Dorsolateral Prefrontal Cortex Is Not Necessary for Spatial Working Memory
}

\author{
(W)Wayne E. Mackey, ${ }^{1}$ @Orrin Devinsky, ${ }^{2}$ Werner K. Doyle, ${ }^{3}{ }^{\circledR}$ Michael R. Meager, ${ }^{1,2}$ and Clayton E. Curtis ${ }^{1,4}$ \\ ${ }^{1}$ Department of Psychology, New York University, New York, New York 10003, Departments of ${ }^{2}$ Neurology and ${ }^{3}$ Neurosurgery, New York University School \\ of Medicine, New York, New York 10016, and ${ }^{4}$ Center for Neural Science, New York University, New York, New York 10003
}

\begin{abstract}
A dominant theory, based on electrophysiological and lesion evidence from nonhuman primate studies, posits that the dorsolateral prefrontal cortex (dlPFC) stores and maintains working memory (WM) representations. Yet, neuroimaging studies have consistently failed to translate these results to humans; these studies normally find that neural activity persists in the human precentral sulcus (PCS) during WM delays. Here, we attempt to resolve this discrepancy. To test the degree to which dlPFC is necessary for WM, we compared the performance of patients with dIPFC lesions and neurologically healthy controls on a memory-guided saccade task that was used in the monkey studies to measure spatial WM. We found that dlPFC damage only impairs the accuracy of memory-guided saccades if the damage impacts the PCS; lesions to dorsolateral dIPFC that spare the PCS have no effect on WM. These results identify the necessary subregion of the frontal cortex for WM and specify how this influential animal model of human cognition must be revised.
\end{abstract}

Key words: frontal eye field; human; lesion; prefrontal cortex; saccade; working memory

\section{Significance Statement}

High-level cognition depends on working memory (WM) as a critical building block, and many symptoms of psychiatric disorders may be the direct result of impaired WM. Canonical theory posits a critical role for the dorsolateral prefrontal cortex (dlPFC) in WM based on studies of nonhuman primates. However, we find that spatial WM in humans is intact after dlPFC damage unless it impacts the more caudal PCS. Therefore, the human dIPFC is not necessary for spatial WM and highlights the need for careful translation of animal models of human cognition.

\section{Introduction}

Working memory (WM) is the process by which one maintains task relevant, but no longer externally available, information. Most higher-level cognitions rely on these maintained WM representations, and some psychiatric symptoms may be the result of their disruption (Park and Holzman, 1992; Goldman-Rakic, 1994; Conklin et al., 2000; Sweeney et al., 2000), which together has motivated an intense search into the neurobiological mechanisms that support WM. According to the dominant theory in the field, neural activity in dorsolateral prefrontal cortex (dlPFC)

Received Sept. 30, 2015; revised Jan. 3, 2016; accepted Jan. 5, 2016.

Author contributions: W.E.M. and C.E.C. designed research; W.E.M., 0.D., W.K.D., M.R.M., and C.E.C. performed research; W.E.M. contributed unpublished reagents/analytic tools; W.E.M., M.R.M., and C.E.C. analyzed data; W.E.M., O.D., W.K.D., M.R.M., and C.E.C. wrote the paper.

This work was supported by National Institutes of Health Grant R01 EY016407 to C.E.C. and the National Science Foundation Graduate Research Fellowship Program to W.E.M. We thank Drs. Karen Blackmon and Elizabeth Phelps for support and management of New York University's Patient Registry for the Study of Perception, Emotion, and Cognition; and Drs. John Golfinos, Uzma Samadani, and Jeffrey Wisoff for patient referrals.

The authors declare no competing financial interests.

Correspondence should be addressed to Dr. Clayton E. Curtis, New York University, 6 Washington Place, New York, NY 10003.E-mail: clayton.curtis@nyu.edu.

DOI:10.1523/JNEUROSCI.3618-15.2016

Copyright $\odot 2016$ the authors $\quad 0270-6474 / 16 / 362847-10 \$ 15.00 / 0$ stores and maintains WM representations (Goldman-Rakic, 1995). The primary evidence for this theory rests on two compelling findings from nonhuman primates. First, neuronal activity in monkey dlPFC neurons selective for the spatial location of a remembered target persists during the retention of that location (Funahashi et al., 1989). Second, experimental lesions of the dlPFC impair the animal's ability to remember locations in the contralesional visual field (Funahashi et al., 1993). However, neuroimaging studies typically fail to find persistent activity in the human dlPFC during spatial WM delays (Courtney et al., 1998; Srimal and Curtis, 2008). Instead, researchers consistently find that neural activity persists more caudally in the precentral sulcus (PCS), the putative human homolog of the monkey frontal eye field (Courtney et al., 1998; Srimal and Curtis, 2008). Therefore, the role of the dlPFC in spatial WM remains inconclusive. This controversy has existed for decades (Curtis and D'Esposito, 2004) and continues to drive theoretical questions about the role of the PFC in WM (Sreenivasan et al., 2014; D'Esposito and Postle, 2015). For instance, research questions whether the PFC actively stores WM representations or directs attention to representations stored in sensory cortices (Lebedev et al., 2004; Emrich et al., 2013; Ester et al., 
a

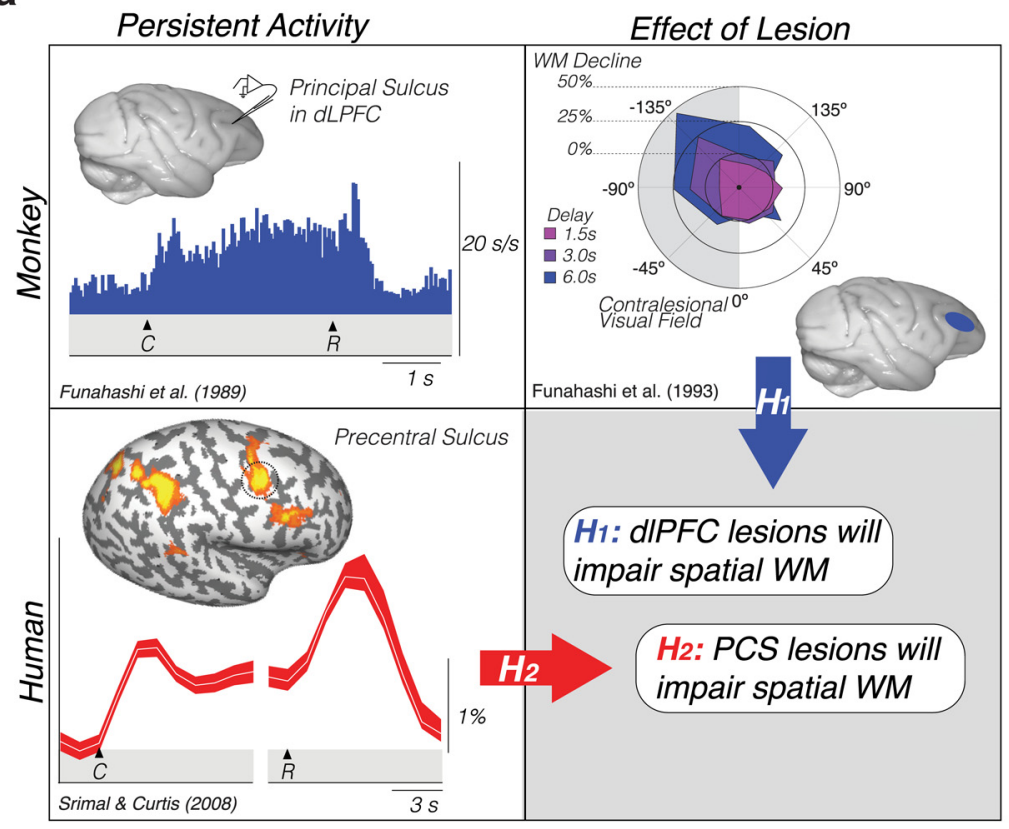

b
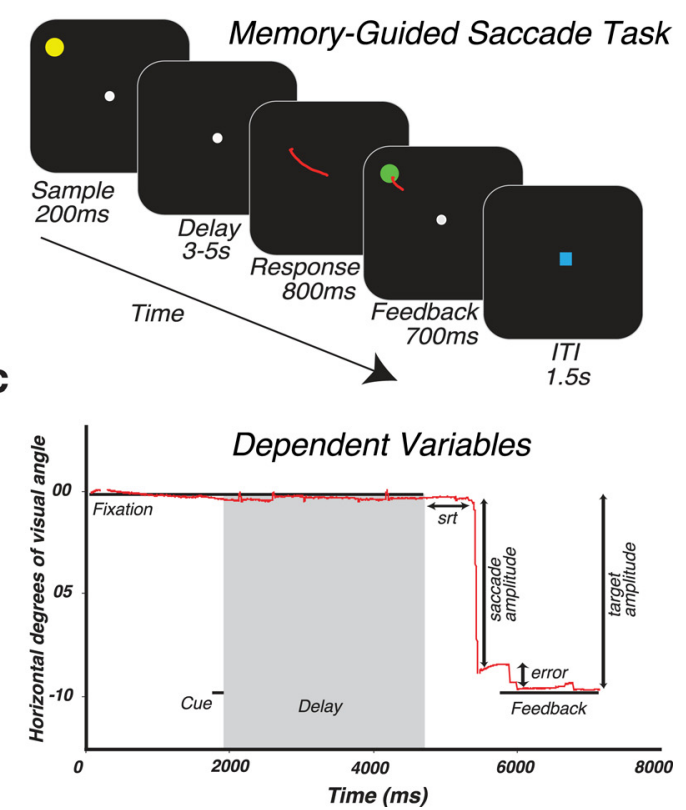

Figure 1. $\quad \boldsymbol{a}$, Rationale and hypotheses of the current study. Neural activity persists in the monkey dIPFC during the retention interval of MGS tasks (Funahashi et al., 1989). Lesions to the monkey dIPFC cause impaired MGSS, especially when made into the visual field contralateral to the lesion (Funahashi et al., 1993). Hypothesis 1: These monkey data predict that lesions to human dIPFC will impair spatial WM performance, including the accuracy of MGSs. However, human neuroimaging studies typically find persistent activity or multivoxel decoding of information restricted to the PCS, posterior to the likely homolog of the monkey principal sulcus in the dIPFC (Courtney et al., 1998; Srimal and Curtis, 2008; Jerde et al., 2012; Sprague et al., 2014). Hypothesis 2: These data predict that lesions to human PCS, not dIPFC, will impair WM performance. $\boldsymbol{b}$, MGS task used to measure WM ability. c, Dependent variables measured in the current study. Derived from eye tracking data, we measured the following: saccadic response time (in milliseconds), time between the offset of the fixation after the delay and the initiation of the MGS; primary saccade error (in degrees of visual angle), the deviation between the position of the eye following the first primary saccade and the target; final saccade error (in degrees of visual angle), the deviation between the target and the position of the last fixation before the target feedback was re-presented; saccade gain (ratio), amplitude of the saccade divided by the amplitude of the target.

2015; Pasternak et al., 2015). In the current study, our goal was to resolve the discrepancies between the prevailing animal model of human WM and evidence from human neuroimaging studies (Fig. 1a) and simply test the hypothesis that damage to the human dlPFC will cause spatial WM impairments. We consider this a critical first step before testing hypotheses about the precise mechanisms (e.g., storage or attention) the PFC may or may not use to support WM.

To test the degree to which dIPFC is necessary for WM, we compared the performance of patients with dIPFC lesions and neurologically healthy controls on a memory-guided saccade (MGS) task similar to that used in the monkey studies (Fig. $1 b)$. In this task, participants remembered the spatial location of a transient stimulus throughout a variable delay period. Shortly thereafter, a cue instructed participants to make an eye movement to the remembered location. To control for the potential effects on visual acuity and saccade execution, participants also performed a visually guided saccade task. We split patients into two groups: those whose lesions encroached on the PCS and those whose lesions did not (Fig. 2). This distinction allowed us to test different predictions based on conflicting results between human neuroimaging and nonhuman primate studies. Whereas nonhuman primate results predict that patients with dlPFC lesions will be impaired in WM performance, human neuroimaging results predict that only those patients whose lesions impact the PCS will be impaired. To assess WM performance, we measured the distance in degrees of visual angle between the cued target location and the participants' eye position after the MGS (Fig. 1c).

\section{Materials and Methods}

Subjects. We recruited 12 patients ( 4 female, mean age 37.4 years, age range 19-46 years) with surgical resections of cortical tissue from the dlPFC (5 right-sided lesions, 7 left-sided lesions) from New York University's Patient Registry for the Study of Perception, Emotion, and Cognition (Fig. 1). Three patients had lesions of the PCS, and the other nine patients had lesions that covered other areas of the dorsolateral PFC but spared the PCS. All patients previously underwent surgical resection to treat cortical tumors or focal epilepsy (Table 1). All patients had no clinical evidence of hemispatial neglect. The amount of time that had passed since their surgery varied from 0.22 years to 16.42 years, with a mean of 3.97 years. It is important to note that, because a significant amount of time had passed since surgical intervention, any potential acute oculomotor deficits would have been resolved. Nine neurologically healthy individuals (3 female, mean age 31.8 years, age range $20-45$ years) served as age-matched experimental controls. All subjects gave written informed consent before participating and were compensated monetarily. All procedures were approved by the human subjects Institutional Review Board at New York University.

Oculomotor procedures. Monocular eye-movement data were collected at either $500 \mathrm{~Hz}$ or $1000 \mathrm{~Hz}$ using an SR Research EyeLink 1000 eyetracker. Subjects sat in a darkened room while their head was stabilized using a chin rest to eliminate head movement and help them remain comfortable during the task. Nine point calibrations were performed at the beginning of each session as well as between runs whenever necessary. Experimental stimuli were displayed against a gray background, and experimental tasks were programmed in MATLAB (The MathWorks) using the MGL toolbox.

Experimental procedures. All subjects performed blocks of two different saccade tasks. Each block consisted of a visually guided saccade (VGS) task followed by an MGS task. Between blocks, subjects were encouraged 
a

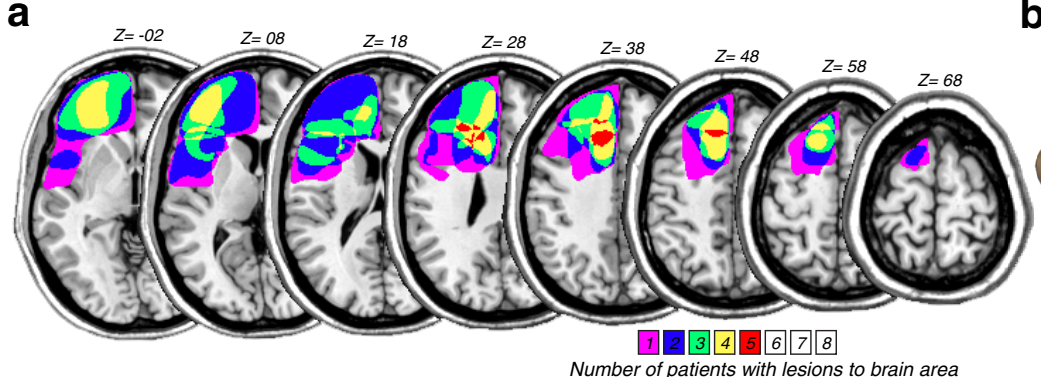

d
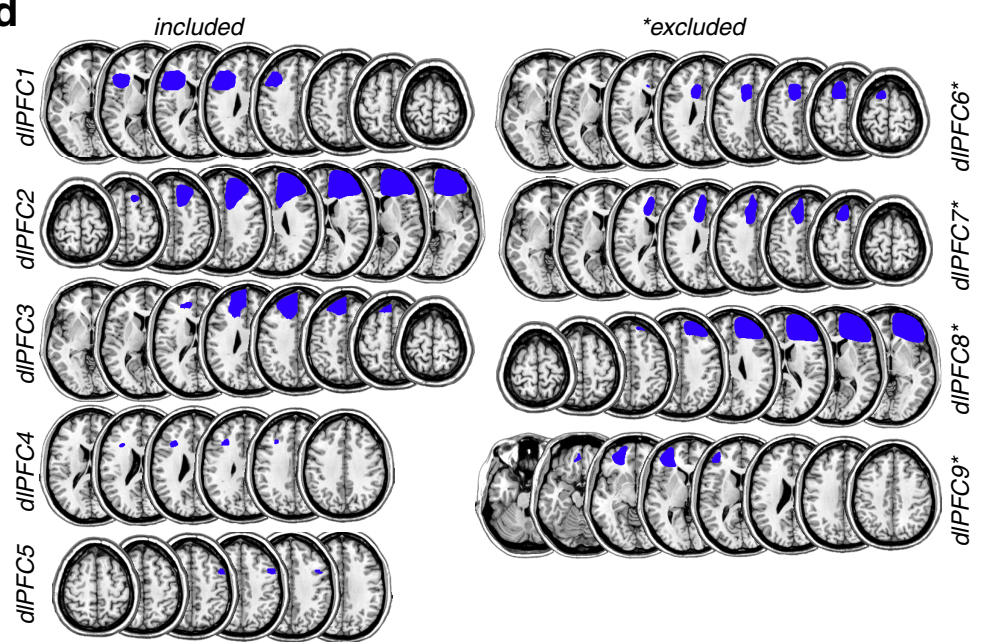

e

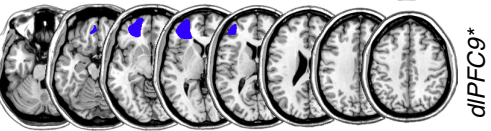

b

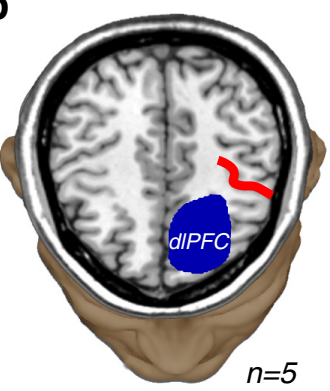

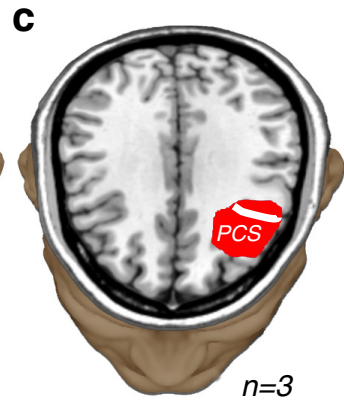
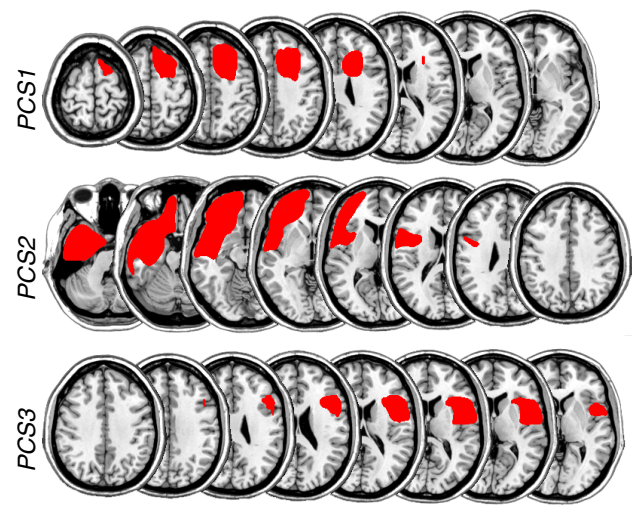

Figure 2. a, dIPFC lesions from patients overlaid on the left hemisphere of structural MRI slices. Five patients had dIPFC lesions that spared the PCS but impacted portions of the middle and superior frontal gyri as can be seen in the lesion overlap reconstruction. Three patients had dIPFC lesions that further encroached upon the PCS. The Z numbers below indicate the slice planes in standardized MNI space (millimeters above anterior commissure). Color bar represents the number of patients $(n=8)$ with lesions to that part of brain. These lesions are more circumscribed than those typically caused by neurovascular events. Patients with right hemisphere lesions $(n=4)$ were flipped to generate the overlap lesion reconstruction. $\boldsymbol{b}$, Example patient (dIPFC2) with a resection of the dIPFC (blue area) that spared the PCS (red line). c, Example patient (PCS1) with a resection (red area) that removed a portion of the PCS (white line). For more details, see Materials and Methods. For demographic, etiologic, and neuropsychologic data, see Table 1.d, Individual lesion reconstructions for each of the PFC patients with resections of dIPFC sparing the PCS. $\boldsymbol{e}$, PCS patients with resections of dIPFC impacting the PCS. Asterisks denote that the patient was excluded because of failure to maintain central fixation when the memory cue appeared in the periphery for at least 50 trials (for details, see Table 3).

Table 1. Demographic data and lesion information on the sample of patients with prefrontal cortex resections ${ }^{a}$

\begin{tabular}{|c|c|c|c|c|c|c|c|c|}
\hline & Age (years) & Gender & Handedness & Education (years) & Lesion size (ml) & Years since resection & Hemisphere & Cause for resection \\
\hline $\mathrm{dIPFC} 1$ & 46 & M & Right & 16 & 41.07 & 5.9 & Left & Glial tumor \\
\hline $\mathrm{dIPFC} 2$ & 41 & $\mathrm{~F}$ & Right & 17 & 139.62 & 16.42 & Right & Epilepsy \\
\hline dIPFC 3 & 23 & $\mathrm{~F}$ & Right & 16 & 36.24 & 0.73 & Left & Oligodendroglioma (low-grade) \\
\hline dIPFC 4 & 45 & M & Right & 16 & 1.98 & 0.88 & Left & Cavernoma \\
\hline dIPFC 5 & 19 & M & Right & 14 & 2.01 & 0.22 & Right & Astrocytoma (low-grade) \\
\hline $\mathrm{dIPFC} 6^{b}$ & 44 & $\mathrm{~F}$ & Right & 18 & 28.36 & 2.5 & Left & Oligodendroglioma (low-grade) \\
\hline $\mathrm{dIPFC} 7^{b}$ & 43 & M & Right & 13 & 33.79 & 4.67 & Left & Neoplasm (glioma) \\
\hline $\mathrm{dIPFC} 8^{b}$ & 33 & M & Right & 17 & 114.03 & 3.65 & Right & Focal cortical dysplasia \\
\hline $\mathrm{dIPFC} 9^{b}$ & 30 & M & Right & 16 & 22.24 & 6.97 & Left & Hamartoma with balloon cells \\
\hline PCS 1 & 39 & M & Right & 14 & 56.56 & 4.3 & Right & Tumor \\
\hline PCS 2 & 27 & M & Right & 18 & 154.45 & 5.78 & Left & Epilepsy \\
\hline PCS 3 & 37 & $\mathrm{~F}$ & Right & 17 & 28.37 & 5.64 & Right & Focal cortical dysplasia \\
\hline
\end{tabular}

${ }^{a} \mathrm{dIPFC}$, dIPFC resection sparing the PCS; PCS, prefrontal cortex resection impacting the PCS.

${ }^{b}$ Excluded because of failure to maintain central fixation when the memory cue appeared in the periphery for a minimum of 50 trials.

to take breaks as necessary to remain both comfortable and alert throughout the experiment. All subjects were instructed to complete as many blocks as possible up to a limit of 10 total blocks (mean blocks completed $=9.1$, range $=4-10$ ).

MGS task. Subjects began by fixating a preparation stimulus (black cross over white dots) at the center of the screen. A target (yellow, $0.5^{\circ}$ diameter dot) then briefly flashed $(200 \mathrm{~ms})$ at a random location of 10 degrees eccentricity from the central fixation point. No targets were presented near the cardinal axes to prevent verbalizing of locations (e.g., up, down). We instructed subjects to remember the location of the dot for a variable delay period $(3,3.5,4,4.5$, or $5 \mathrm{~s})$. At the end of the delay period, a sound coupled with the disappearance of the fixation point instructed the subject to shift their gaze to the spatial location of the target they were holding in memory. After $800 \mathrm{~ms}$, the target was re-presented on the screen (as a green dot for $700 \mathrm{~ms}$ ) to provide feedback to the subject. They were trained to look at the target if their gaze was incorrect (i.e., displaced from the target). Afterward, an intertrial interval (blue square at central fixation, $1.5 \mathrm{~s}$ ) was displayed to notify subjects that the current trial had ended and a new one was about to begin (Fig. 1b). Each run consisted of a total of 30 trials. 
Table 2. Neuropsychological scores from patients following prefrontal cortex resections ${ }^{a}$

\begin{tabular}{|c|c|c|c|c|c|c|c|c|c|c|c|c|c|}
\hline & \multicolumn{6}{|l|}{ WAIS-IV } & \multicolumn{2}{|c|}{ Digit Span } & \multicolumn{5}{|c|}{ WCST } \\
\hline & Cognitive level & FSIQ & $\mathrm{VCl}$ & PRI & PSI & WMI & Forw & Back & Cat & $\mathrm{PE}$ & NPE & $\mathrm{CL}$ & LTL \\
\hline dIPFC 1 & Superior & 124 & 132 & 111 & 111 & 122 & 81 & 36 & 3 & 19 & 34 & 25 & 21 \\
\hline dIPFC 2 & Average & 106 & 110 & 92 & 111 & 108 & 62 & 16 & 0 & 3 & 2 & 1 & 1 \\
\hline dIPFC 3 & Average & 100 & 122 & 94 & 92 & 83 & 64 & 32 & 5 & 50 & 45 & 55 & 25 \\
\hline dIPFC 4 & Average & 100 & 103 & 98 & 89 & 111 & 96 & 31 & 4 & 27 & 27 & 34 & 16 \\
\hline dIPFC 5 & High average & 118 & 150 & 102 & 94 & 105 & 85 & 90 & 1 & 10 & 2 & 2 & 1 \\
\hline $\operatorname{dIPFC} 6^{b}$ & High average & 119 & 122 & 113 & 114 & 111 & 81 & 86 & 5 & 42 & 61 & 45 & 25 \\
\hline $\mathrm{dIPFC} 7^{b}$ & Low average & 82 & 98 & 86 & 71 & 80 & 95 & 86 & 3 & 14 & 12 & 16 & 16 \\
\hline dIPFC $8^{b}$ & Low average & 80 & 83 & 86 & 84 & 80 & 97 & 97 & 3 & 5 & 34 & 16 & 5 \\
\hline $\operatorname{dIPFC} 9^{b}$ & Superior & 126 & 130 & 115 & 114 & 122 & 62 & 19 & 4 & 27 & 92 & 58 & 25 \\
\hline PCS 1 & Average & 99 & 100 & 97 & 97 & 100 & 62 & 86 & 5 & 70 & 61 & 55 & 25 \\
\hline PCS 2 & High average & 110 & 108 & 109 & 105 & 108 & 86 & 19 & 5 & 77 & 50 & 45 & 25 \\
\hline PCS 3 & Low average & 82 & 95 & 88 & 74 & 83 & 97 & 97 & 0 & 2 & 1 & 1 & 1 \\
\hline
\end{tabular}

${ }^{a}$ dIPFC, dIPFC resection sparing the PCS; PCS, prefrontal cortex resection impacting the PCS; FSIQ, Full-Scale Intelligence Quotient; VCI, Verbal Comprehension Index; PRI, Perceptual Reasoning Index; PSI, Processing Speed Index; FSIQ, VCI, $\mathrm{PRI}, \mathrm{PSI}$, and WMI were derived from the WAIS-IV and have a mean of 100 and SD of 15. Digit Span: Forw, immediate recall of aurally presented digits in the order given (in performance percentiles); Back, same but recall in reverse order; Cat, number of categories completed; PE, perseverative errors; $\mathrm{NPE}$, nonperseverative errors; $\mathrm{CL}$, conceptual level responding; LTL, learning to learn (all in percentiles relative to normative performance from general population matched for age and education).

${ }^{b}$ Excluded because of failure to maintain central fixation when the memory cue appeared in the periphery for a minimum of 50 trials.

Table 3. Descriptions of the amount, usability, and reasons for excluding trials during the MGS task used with the study sample ${ }^{a}$

\begin{tabular}{|c|c|c|c|c|c|c|c|c|}
\hline Group & Trials & Usable trials (\%) & No MGS (\%) & No left MGS (\%) & No right MGS (\%) & Broke fixation (\%) & Broke fixation left (\%) & Broke fixation right (\%) \\
\hline CTL 1 & 270 & 78 & 0 & 0 & 0 & 22 & 14 & 8 \\
\hline CTL 2 & 300 & 87 & 7 & 4 & 3 & 6 & 4 & 2 \\
\hline CTL 3 & 300 & 91 & 4 & 2 & 2 & 5 & 3 & 2 \\
\hline CTL 4 & 300 & 86 & 3 & 2 & 1 & 11 & 5 & 6 \\
\hline CTL 5 & 210 & 91 & 4 & 3 & 1 & 5 & 0 & 5 \\
\hline CTL 6 & 120 & 99 & 0 & 0 & 0 & 1 & 1 & 0 \\
\hline CTL 7 & 300 & 95 & 3 & 2 & 1 & 2 & 2 & 0 \\
\hline CTL 8 & 300 & 55 & 14 & 7 & 7 & 31 & 15 & 16 \\
\hline CTL 9 & 300 & 92 & 4 & 2 & 2 & 4 & 2 & 2 \\
\hline dIPFC 1 & 300 & 97 & 1 & 1 & 0 & 2 & 1 & 1 \\
\hline dIPFC 2 & 240 & 62 & 14 & 8 & 6 & 25 & 11 & 14 \\
\hline dIPFC 3 & 240 & 88 & 1 & 0 & 1 & 11 & 7 & 4 \\
\hline dIPFC 4 & 300 & 82 & 1 & 1 & 0 & 17 & 10 & 7 \\
\hline dIPFC 5 & 300 & 81 & 6 & 3 & 3 & 13 & 7 & 6 \\
\hline $\mathrm{dIPFC} \sigma^{b}$ & 300 & 0 & 100 & 56 & 44 & 100 & 56 & 44 \\
\hline $\operatorname{dIPFC} 7^{b}$ & 300 & 0 & 78 & 41 & 37 & 100 & 52 & 48 \\
\hline $\operatorname{dIPFC} 8^{b}$ & 150 & 28 & 48 & 22 & 26 & 50 & 26 & 24 \\
\hline $\mathrm{dIPFC} 9^{b}$ & 300 & 0 & 97 & 52 & 45 & 100 & 55 & 45 \\
\hline PCS 1 & 300 & 54 & 8 & 5 & 3 & 37 & 18 & 19 \\
\hline PCS 2 & 300 & 58 & 1 & 1 & 0 & 41 & 26 & 14 \\
\hline PCS 3 & 300 & 62 & 24 & 13 & 11 & 17 & 7 & 10 \\
\hline
\end{tabular}

${ }^{a}$ dIPFC, dIPFC resection sparing the PCS; PCS, prefrontal cortex resection impacting the PCS; No MGS, percentage of trials in which the subject did not generate an MGS before the feedback was presented; No left/right MGS, same broken down by whether the cue was in the left or right visual field; Broke fixation, looked away from the fixation point (almost always towards the location of the visual cue) during the cue or delay period; Broke fixation left/right, same broken down by whether the cue was in the left or right visual field.

${ }^{b}$ Excluded because of failure to maintain central fixation when the memory cue appeared in the periphery for a minimum of 50 trials.

Visually guided saccade task. The VGS task was introduced to control for confounds of visual acuity and saccade preparation because they do not include any memory component and require participants only to follow a target location on the screen. Although most oculomotor deficits resulting from lesions resolve themselves rather quickly, it was still possible that some oculomotor deficits could exist. Therefore, this task also served as a baseline performance of saccade accuracy, gain, and response time. For each run, a target (green dot) appeared for $1200 \mathrm{~ms}$ in one of the same target locations from the MGS experiment, then jumped to another location in the other hemifield, repeating until 30 saccades had been made. Subjects were instructed just to follow the target with their eyes, maintaining their gaze directly on it until the position changed.

Analysis. Eye-movement data were transformed into degrees of visual angle using a third-order polynomial algorithm that fit eye positions to known spatial locations and then scored offline with an in-house MATLAB function-graphing toolbox (iEye). Saccades were defined as when eye velocity exceeded 30 degrees/s or when velocity failed to reach 30 degrees/s, confirmed by visual inspection. Error was defined as dis- tance between the response location and the target location, expressed in degrees of visual angle. Saccadic gain was examined as another expression of targeting error and was defined as the ratio of saccade amplitude/target eccentricity. Saccadic response time represents the amount of time, in milliseconds, between the onset of the response cue and saccade onset.

Error and gain were calculated for the initial saccade after central fixation offset (primary saccade) as well as the last corrective saccade before target feedback was presented (final saccade). Trials where saccadic response time exceeded $900 \mathrm{~ms}$ or were $<100 \mathrm{~ms}$ were discarded from analysis. Trials where subjects prematurely broke fixation were also discarded. We then excluded subjects who were unable to complete at least 50 total trials from further analysis. Four patients with PFC damage were excluded because they failed to maintain central fixation when the memory cue appeared in the periphery for at least 50 trials. These patients are marked in Figure 1c. Tables 2 and 3 indicate neuropsychological and task behavior.

Patients were split into two groups: those whose dlPFC lesions extended into the PCS and those whose lesions spared the PCS. Because 
a
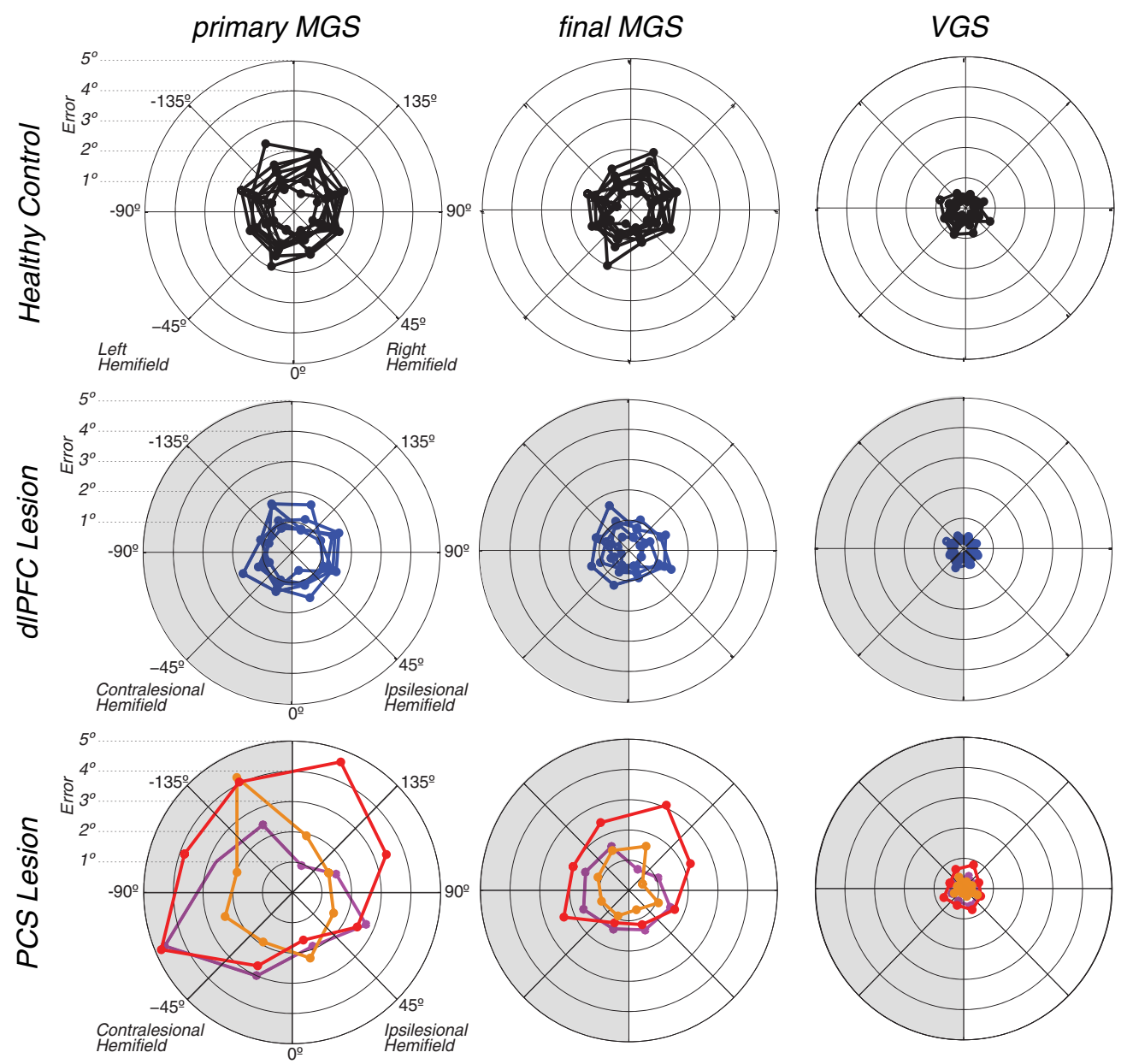

b
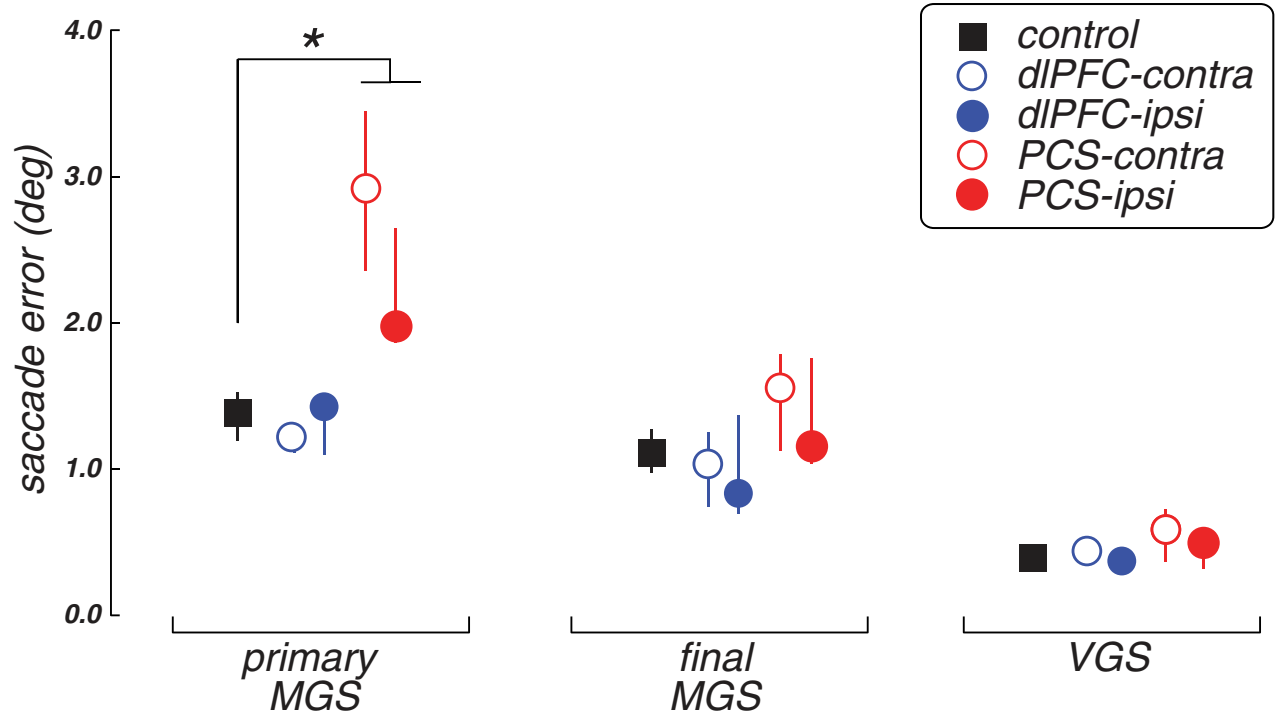

Figure 3. Performance on WM (MGS) and control (VGS) tasks. $\boldsymbol{a}$, Radial histograms of the accuracy of primary MGSs, the final position of the eye after corrective saccades, but before feedback, and the accuracy of visually guided saccades. Each line indicates the mean error of an individual patient or healthy control at each radial location. Shaded half represents performance in the visual field contralateral to the lesion. $\boldsymbol{b}$, Group average error on MGS and VGS tasks. Error bars indicate SEM. Patients with PCS lesions generated primary MGSs with more spatial error than controls. ${ }^{*} p<$ 0.01. The individual performance is plotted in Figure 4.

patient groups consisted of both left and right lesions, we grouped results into contralesional and ipsilesional categories. In the control group, we compared leftward and rightward trials across all performance metrics (Wilcoxon Rank-Sum). Because no significant differences were found, we averaged control results into one group category. We compared the MGS accuracies within each group and found that performance did not depend on the narrow range of delays used (Wilcoxon Rank-Sum). Therefore, we collapsed our analyses across the different delays. Statisti- 
cal analysis of performance results across groups was performed (Kruskal-Wallis ANOVA) for all metrics. When results were statistically significant, we compared ipsilesional and contralesional patient performance with controls (Wilcoxon Rank-Sum).

Neuropsychological examination. A trained, licensed, neuropsychologist (M.R.M.) administered a battery of neuropsychological tests. The Wechsler Adult Intelligence Scales, Edition IV (WAIS-IV) (Wechsler et al., 2008) was used to measure general intellectual functions. The WAIS-IV yields four primary indices: Verbal Comprehension, Perceptual Reasoning, Working Memory, and Processing Speed, as well as a Full-Scale Intelligence Quotient, a composite of the four indices. We report the scores (standard scores) relative to the agematched normative sample of the WAIS-IV, with a mean of $100(S D=15)$. The Working Memory Index contains two subtests, Digit Span and Arithmetic. Digit Span measures basic short-term memory, attention, and concentration and was calculated for Digits Forward (number strings recalled in the same order as presented), Digits Backward (number strings recalled in reverse order as presented), and Digit Sequencing (number strings recalled in numerical order). We report cumulative percentiles of each patient's performance for the Digit Span Forward and Backward tests. Patients were also manually administered the Wisconsin Card Sorting Test (WCST) 64 Card Version (Greve, 2001), which is a well-established measure of concept formation and problem solving and is sensitive to "executive" dysfunction following PFC damage (Milner, 1963; Drewe, 1974; Stuss et al., 2000). The test yields several measures of performance, such as the number of completed categories, the number of perseverative and nonperseverative errors, conceptual level responses (measure of insight into sorting principles), and learning to learn (change in conceptual efficiency across the changing categories). We report the percentile of the patient's performance for the WCST relative to normative performance from the WCST-64 normative sample matched for age and education.

\section{Results}

In contrast to the disruption in MGS accuracy caused by damage to monkey dlPFC, here we found that damage to human dlPFC had no effects on MGSs. The accuracy (Wilcoxon Rank-Sum, $p=0.36$ ), gain (Wilcoxon Rank-Sum, $p=0.41$ ), and response times (Wilcoxon Rank-Sum, $p=0.19$ ) of their MGSs were all no different from the controls (Figs. 3-5). Thus, despite large and variable lesions of the dlPFC, these patients had completely normal spatial WM. The PCS patients, on the other hand, were significantly impaired compared with the controls. They made hypometric MGSs with significantly higher error (Wilcoxon Rank-Sum, $p=0.009$ ), reduced gain (Wilcoxon Rank-Sum, $p=$ 0.002 ), and slowed response times (Wilcoxon Rank-Sum, $p=$ 0.009) (Figs. 3-5).

In general, the patients' performance on neuropsychological tests of intelligence, memory, and speeded responding were within normal limits (Table 2), making it unlikely that perfor- a

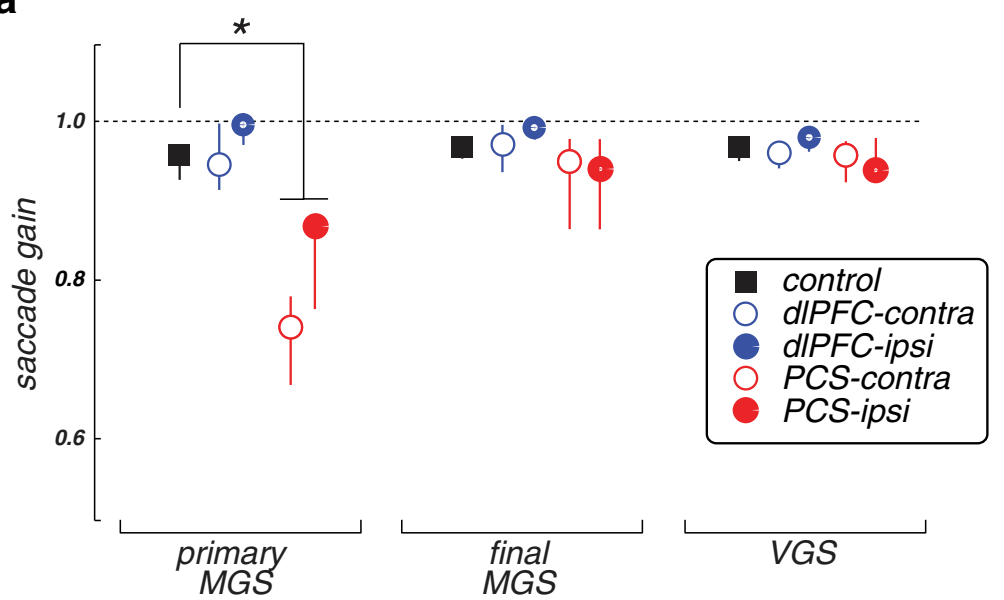

b

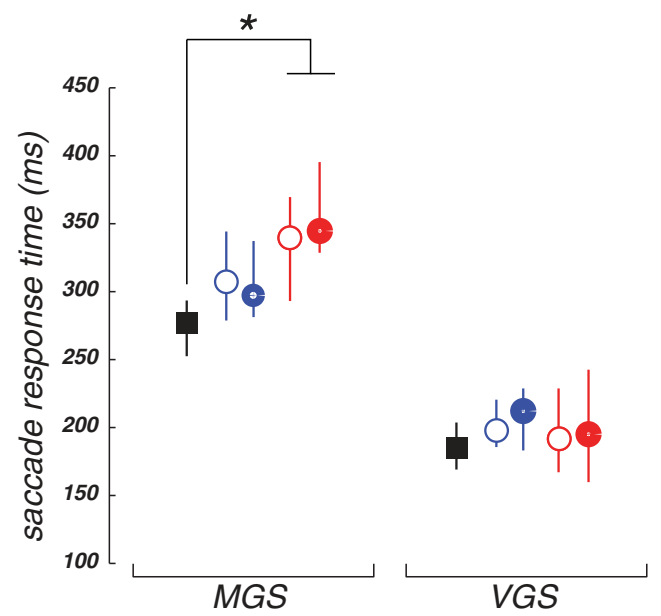

Figure 5. Group average $(\boldsymbol{a})$ saccade gains and $(\boldsymbol{b})$ response times of MGS and control VGS tasks. The MGS errors made by the PCS patients were hypometric in gain and slower ( $\sim 75 \mathrm{~ms})$ compared with the control group. ${ }^{*} p<0.05$. Error bars indicate SEM. 
Table 4. Correlations between demographic, neuropsychologic, and lesion variables with dependent variables derived from performance on MGS task ${ }^{a}$

\begin{tabular}{|c|c|c|c|c|c|c|c|c|c|c|c|c|c|c|}
\hline & \multirow[b]{2}{*}{ Age (years) } & \multirow{2}{*}{$\begin{array}{l}\text { Years since } \\
\text { resection }\end{array}$} & \multirow{2}{*}{$\begin{array}{l}\text { Lesion size } \\
(\mathrm{ml})\end{array}$} & \multicolumn{4}{|l|}{ WAIS-IV } & \multicolumn{2}{|l|}{ Digit Span } & \multicolumn{5}{|l|}{ WCST } \\
\hline & & & & FSIQ & $\mathrm{VCl}$ & PRI & WMI & Forw & Back & Cat & $\mathrm{PE}$ & NPE & $\mathrm{CL}$ & LTL \\
\hline $\begin{array}{l}\text { Primary saccade } \\
\quad \text { error, contralateral }\end{array}$ & $-0.21(0.61)$ & $-0.04(0.91)$ & $0.07(0.85)$ & $-0.62(0.10)$ & $-0.68(0.06)$ & $-0.16(0.70)$ & $-0.41(0.31)$ & $-0.02(0.97)$ & $0.57(0.14)$ & $0.19(0.64)$ & $0.44(0.27)$ & $0.38(0.36)$ & $0.29(0.49)$ & $0.20(0.63)$ \\
\hline $\begin{array}{l}\text { Primary saccade } \\
\text { error, ipsilateral }\end{array}$ & $-0.48(0.23)$ & $-0.01(0.97)$ & $0.23(0.58)$ & $-0.43(0.28)$ & $-0.51(0.20)$ & $-0.06(0.88)$ & $-0.36(0.37)$ & $-0.31(0.46)$ & $0.48(0.23)$ & $0.30(0.48)$ & $0.60(0.11)$ & $0.48(0.23)$ & $0.39(0.33)$ & $0.27(0.51)$ \\
\hline $\begin{array}{l}\text { Saccadic response } \\
\text { time, contralateral }\end{array}$ & $0.22(0.59)$ & $0.71(0.04)$ & $0.68(0.06)$ & $0.10(0.80)$ & $-0.12(0.77)$ & $0.03(0.94)$ & $0.30(0.46)$ & $0.19(0.66)$ & $-0.18(0.66)$ & $-0.56(0.17)$ & $-0.25(0.55)$ & $-0.46(0.25)$ & $-0.59(0.13)$ & $-0.51(0.20)$ \\
\hline $\begin{array}{l}\text { Saccadic response } \\
\text { time, ipsilateral }\end{array}$ & $0.10(0.81)$ & $0.65(0.08)$ & $0.77(0.02)^{*}$ & $-0.01(0.97)$ & $-0.32(0.43)$ & $0.08(0.84)$ & $0.24(0.56)$ & $0.10(0.81)$ & $-0.13(0.77)$ & $-0.30(0.47)$ & $0.06(0.90)$ & $-0.18(0.67)$ & $-0.32(0.44)$ & $-0.29(0.50)$ \\
\hline
\end{tabular}

${ }^{a}$ Values are correlation coefficient $(p)$.

*Significant after correcting for multiple comparisons using false discovery rate.

mance on the MGS task could be attributed to general cognitive dysfunction. We found that MGS accuracy did not correlate with demographic factors, such as age, or clinical factors, such as size of lesion or time between resection and testing (Table 4). Thus, the results cannot be dismissed due to age-related cognitive decline often found in patients with neurovascular damage (e.g., stroke), or to reorganization of function following brain damage. We only found that slower initiation of MGSs was associated with a larger volume of resected tissue. Such slowing hardly aligns with predictions from PFC theories of WM. Moreover, MGS performance did not correlate with clinical neuropsychological test performance, including indices of intelligence and auditory WM (Table 3). In general, however, the dlPFC patients had difficulties with the WCST, a sensitive measure of executive dysfunction, as evidenced by low scores on one or more of the performance indices (Table 2). For instance, they had particular difficulties adapting to the changing sorting rules over time, as measured by the learning to learn index (mean dlPFC performance $=13$ th percentile).

On average, PCS patients generated MGSs that fell short of the memorized target location by 3 degrees when directed into the contralesional hemifield and by 2 degrees into the ipsilesional hemifield (Figs. 3, 4). Upon closer examination of the pattern of saccades, however, we noticed that the PCS patients often made several quick saccades following the primary hypometric MGS, but before any visual feedback about the target location (Fig. 6). These secondary corrective saccades were not randomly directed; they were almost always directed toward the location of the memory target and eventually abolished any differences in WM accuracy between the PCS patients and controls (error $\mathrm{df}=4, \mathrm{H}=$ $7.5, p=0.11$; gain $\mathrm{df}=4, \mathrm{H}=4.64, p=0.32)$. They were compensatory in nature as they significantly reduced the overall error in all three PCS patients (Wilcoxon Rank-Sum, PCS1, $p=$ $1.5-15$; PCS2, $p=1.0-12$; PCS3, $p=2.2-6)$. The PCS patients generated more of these corrective saccades during the memory response epoch and had more trials with corrective saccades than the dlPFC patients or controls (Fig. 6). Therefore, given time, the PCS patients compensated for initially inaccurate MGSs.

\section{Discussion}

Patients with damage to the dlPFC that spared the PCS have spatial WM abilities that are indistinguishable from healthy controls. These patients typically made either a single MGS that fell within one degree of the memorized target location on average or an accurate first saccade followed by a small corrective one that only slightly improved accuracy between one-fourth and onehalf of a degree. These results have several important implications for PFC theory. First, lesions to the human dlPFC did not impact spatial WM abilities, a finding inconsistent with the dominant theory of PFC and the supporting monkey data that is taught in most contemporary neuroscience textbooks (Purves, 2012; Kan- del, 2013; Squire, 2013; Gazzaniga et al., 2014). Because we used a similar WM task used in the monkey studies, and we compared lesions with homologous dlPFC areas, we conclude that there must be some differences between the species in the necessary neural substrates for WM. This discrepancy highlights the need for careful cross-species translational work, a need that will continue to be taxed as we, as a field, target the neurobiological mechanisms of higher-level cognitions.

Our results appear incompatible with two previous studies reporting that strokes affecting the human dIPFC impair the accuracy of MGSs (Pierrot-Deseilligny et al., 1991; Ploner et al., 1999). However, the strokes in these studies damaged large portions of the PFC, including the PCS, which we agree causes hypometric MGSs. We considered alternative explanations to our conclusion that the human dlPFC is not necessary for spatial WM. Neural plasticity might compensate for loss of function following brain damage (Voytek et al., 2010). A distributed network of brain areas likely supports WM functions. Indeed, spatially tuned activity in neurons persist during the delay periods of MGS tasks in a distributed network of monkey brain areas, including the dlPFC (Funahashi et al., 1989), frontal eye field (Bruce and Goldberg, 1985), lateral intraparietal area (Gnadt and Andersen, 1988), and superior colliculus (Paré and Wurtz, 1997). It is possible that this network reorganized to compensate for the dlPFC resections. Although possible, we found no relationship between WM performance and the time between testing and the surgeries, which ranged from 10 weeks to 16 years. Therefore, if the WM network reorganized to compensate for the loss of the dlPFC tissue, this process fully restored WM ability within 10 weeks and showed no further reorganization. Finally, it is unclear how and why such plasticity might occur when only the dlPFC and not the adjacent PCS tissue was resected. Future studies should directly address the role of plasticity by comparing the effects of transient inactivation (e.g., transcranial magnetic stimulation) and permanent damage. Only then can we rule out the possibility that network reorganization compensated for the resections to dlPFC. It is also unlikely that our WM measure was insensitive to potential dysfunction because MGS accuracy was indeed impaired after PCS damage. Despite that patients maintained only a single location in WM for only 3-5 s, our measurements were sensitive enough to detect small differences, if they existed, in the precision of WM down to the limits of the eyetracker ( $\sim 1 / 4$ of a degree). There were slight differences in task procedures between the monkey and our human study. Specifically, Funahashi et al. (1993) used the same fixed eight target locations, whereas we used randomly changing target locations, and the monkeys were rewarded with juice after each correct trial, while the patients only received visual feedback. One would predict that the differences would make the task relatively harder and less motivating for the humans with dlPFC lesions, who had no 
a

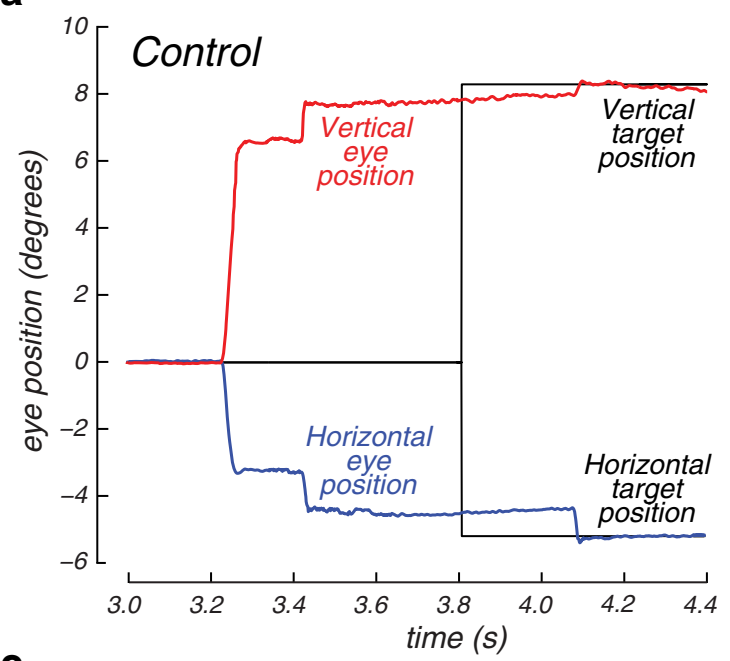

C

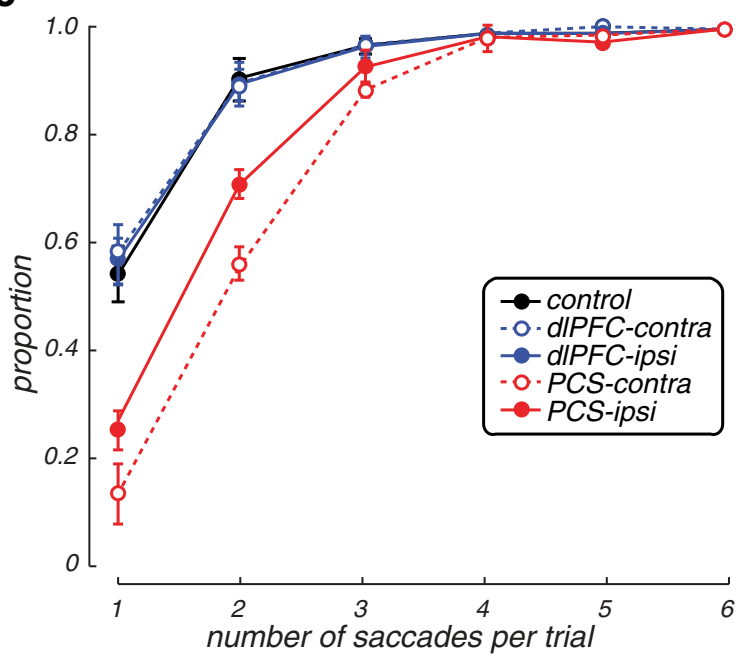

b
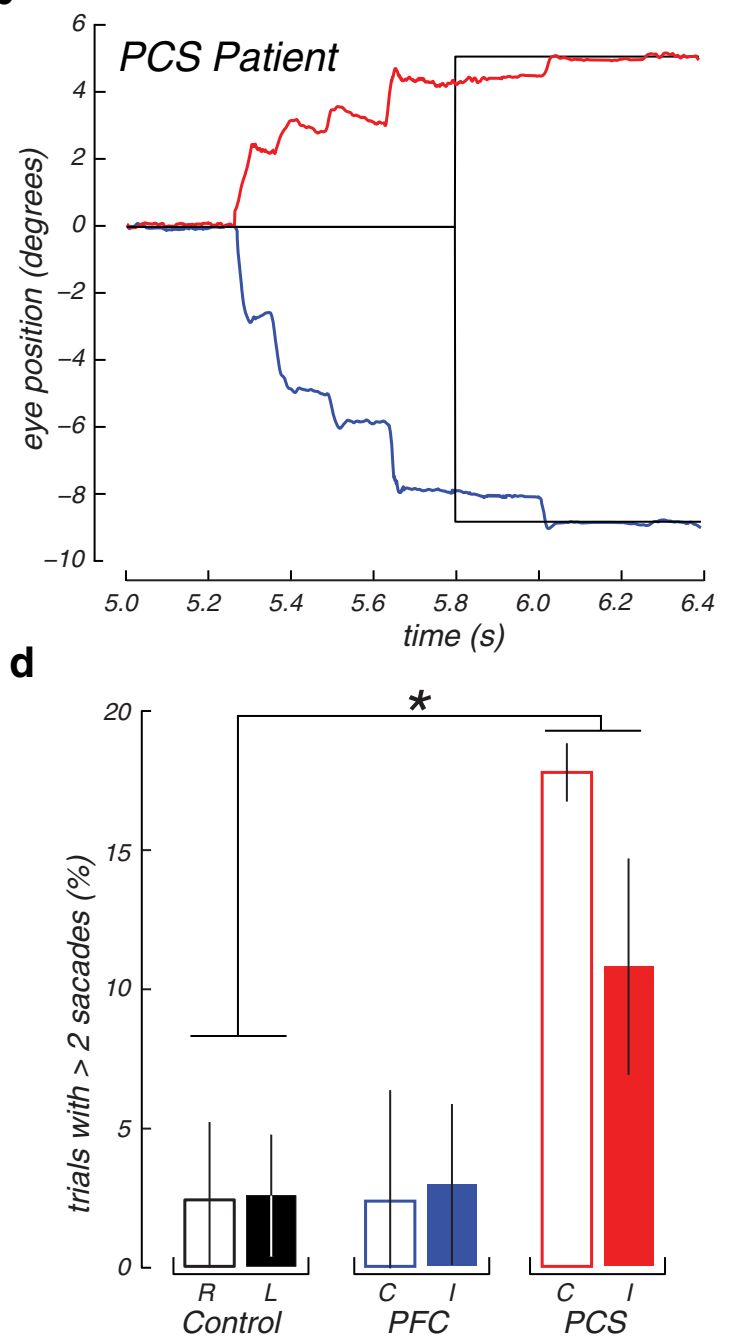

Figure 6. Corrective saccades following initial MGSs. $\boldsymbol{a}$, Example trace of typical MGS from a healthy control participant showing a primary MGS to the upper left quadrant, quickly followed by a single corrective saccade that brings the eye within a degree of the remembered target (black trace). Later the eye fixates that target shortly after it is re-presented as feedback. $\boldsymbol{b}$, Example trace from a patient with a PCS lesion generating an extremely hypometric primary MGS that is followed by multiple rapid corrective saccades that eventually bring the eye close to the remembered target. c, Cumulative distribution of the frequency ( $y$-axis) of single and multiple MGSs ( $x$-axis) by group and visual field with respect to lesion. PCS patients generated many more multistep MGSs, especially into the contralesional hemifield. Error bars indicate SEM. $\boldsymbol{d}$, Percentage of trials in which more than two saccades were made. The example trial depicted in $\boldsymbol{a}$ is an example of a trial that would not be counted ( $n=2$ saccades), whereas the example in $\boldsymbol{b}$ is an example that would be counted ( $n=4$ saccades). PCS patients had many more trials with more than two saccades, especially into the contralesional visual field, compared with controls. ${ }^{*} p<0.05$. Open bars represent trials in which the target was in the contralesional visual field (or in the case of controls, the right visual field). Closed bars represent ipsilesional (or left visual field for controls). Error bars indicate SEM.

difficulties with the task. Therefore, and with these caveats in mind, we conclude that the human dlPFC is not necessary for the maintenance of spatial information in WM and current theory needs revision.

We suggest two important revisions. First, the human dlPFC may be necessary for executive control functions instead of the storage of WM representations. Although the goal of the current study was not to test such an alternative hypothesis, the neuropsychological data collected on our patients suggest that executive functions may have been compromised. The dlPFC patients had difficulties with the WCST, a sensitive measure of executive dysfunction. Damage to dlPFC did not consistently affect neuropsychological measures of general intelligence. Moreover, and in agreement without our findings from the MGS task, WM span for aurally presented numbers, as measured by the Digit Span task, was also within normal limits, suggesting that PFC damage may spare even other forms of WM (D'Esposito and Postle, 1999). One form of the theoretical revision, therefore, should emphasize executive control, rather than WM functions (Sreenivasan et al., 2014; D'Esposito and Postle, 2015). Indeed, in a recent commentary, Tsujimoto and Postle (2012) argue that lesions to the monkey dlPFC do not cause WM impairments despite inaccurate MGSs. They reinterpreted published data and showed that misdirected saccades were often directed to the target location on the previous trial, and these errors were often followed by corrective saccades made to the correct target on the current trial. They conclude that dlPFC lesions affect the animal's ability to select the correct response between the past and current trials, nominally a control, not mnemonic, function (Tsujimoto and Postle, 2012).

Second, the patients with PCS lesions made consistently hypometric MGSs into the contralesional hemifield, similar to prior studies of monkeys with frontal eye field lesions (Sommer and 
Tehovnik, 1997; Dias and Segraves, 1999). Therefore, the human PCS, and not more anterior dlPFC, may be a critical substrate for maintaining spatial WM representations. Funahashi et al. (1993) used the term "mnemonic scotoma" to draw an analogy between the loss of vision in the contralateral hemifield following damage to early visual cortex and the loss of WM for items in the contralateral hemifield following damage to the monkey dlPFC. Interestingly, hemianopsia (the loss of visual acuity in one hemifield) results in staircase-like sequences of hypometric saccades made to visual targets in the contralesional visual field in humans (Meienberg et al., 1981; Rath-Wilson and Guitton, 2015) similar to those made by the PCS patients to memorized, but not visual, targets.

Nonetheless, we must be cautious while concluding that the PCS lesions impaired the ability to store and maintain spatial WM representations because the patients made quick follow-up saccades that corrected their initial error. All previous studies that concluded that PFC damage, in monkeys or humans, impairs MGSs only measured the accuracy of the first saccade (Funahashi et al., 1989; PierrotDeseilligny et al., 1991; Ploner et al., 1999). Yet, the accuracy of the first saccade and the accuracy of the final position before feedback likely reflect different aspects of WM. They do have different developmental trajectories (Luna et al., 2004), different profiles of adaptation (Srimal and Curtis, 2010), and different patterns of dysfunction in schizophrenia (Krappmann and Everling, 1998). Because PCS patients made normal visually guided saccades, we can rule out basic visual and motor impairments, including transforming external visual targets into saccade plans. We reasoned that damage to the PCS distorts the transformation of the memorized retinal location into the saccade plan. Human PCS contains retinotopic maps of prioritized space (Jerde et al., 2012), and accurate MGSs may naturally depend on a readout of the PCS population activity by the superior colliculus (Sommer and Wurtz, 2001). However, spatial WM representations are unlikely to be stored in a single brain area, such as the human dIPFC. Rather, they are stored in networks distributed across multiple topographic maps, cortical and subcortical, including the ones in parietal (Medendorp et al., 2006; Schluppeck et al., 2006; Srimal and Curtis, 2008; Sheremata et al., 2010) and occipital cortex (Saber et al., 2015) that are intact in our patients. We propose that these maps provide the inputs that may compensate for the initial faulty readout from the damaged PCS maps.

\section{References}

Bruce CJ, Goldberg ME (1985) Primate frontal eye fields: 1. Single neurons discharging before saccades. J Neurophysiol 53:603-635. Medline

Conklin HM, Curtis CE, Katsanis J, Iacono WG (2000) Verbal working memory impairment in schizophrenia patients and their first-degree relatives: evidence from the digit span task. Am J Psychiatry 157:275-277. CrossRef Medline

Courtney SM, Petit L, Maisog JM, Ungerleider LG, Haxby JV (1998) An area specialized for spatial working memory in human frontal cortex. Science 279:1347-1351. CrossRef Medline

Curtis CE, D'Esposito M (2004) The effects of prefrontal lesions on working memory performance and theory. Cogn Affect Behav Neurosci 4: 528-539. CrossRef Medline

D’Esposito M, Postle BR (1999) The dependence of span and delayedresponse performance on prefrontal cortex. Neuropsychologia 37: 1303-1315. CrossRef Medline

D'Esposito M, Postle BR (2015) The cognitive neuroscience of working memory. Annu Rev Psychol 66:115-142. CrossRef Medline

Dias EC, Segraves MA (1999) Muscimol-induced inactivation of monkey frontal eye field: effects on visually and memory-guided saccades. J Neurophysiol 81:2191-2214. Medline

Drewe EA (1974) The effect of type and area of brain lesion on Wisconsin Card Sorting Test performance. Cortex 10:159-170. CrossRef Medline

Emrich SM, Riggall AC, Larocque JJ, Postle BR (2013) Distributed patterns of activ- ity in sensory cortex reflect the precision of multiple items maintained in visual short-term memory. J Neurosci 33:6516-6523. CrossRef Medline

Ester EF, Sprague TC, Serences JT (2015) Parietal and frontal cortex encode stimulus-specific mnemonic representations during visual working memory. Neuron 87:893-905. CrossRef Medline

Funahashi S, Bruce CJ, Goldman-Rakic PS (1989) Mnemonic coding of visual space in the monkey's dorsolateral prefrontal cortex. J Neurophysiol 61:331-349. Medline

Funahashi S, Bruce CJ, Goldman-Rakic PS (1993) Dorsolateral prefrontal lesions and oculomotor delayed-response performance: evidence for mnemonic "scotomas." J Neurosci 13:1479-1497.

Gazzaniga MS, Ivry RB, Mangun GR (2014) Cognitive neuroscience: the biology of the mind, Ed 4. New York: Norton.

Gnadt JW, Andersen RA (1988) Memory related motor planning activity in posterior parietal cortex of macaque. Exp Brain Res 70:216-220. Medline

Goldman-Rakic PS (1994) Working memory dysfunction in schizophrenia. J Neuropsychiatry Clin Neurosci 6:348-357. CrossRef Medline

Goldman-Rakic PS (1995) Cellular basis of working memory. Neuron 14: 477-485. CrossRef Medline

Greve KW (2001) The WCST-64: a standardized short-form of the Wisconsin Card Sorting Test. Clin Neuropsychol 15:228-234. CrossRef Medline

Jerde TA, Merriam EP, Riggall AC, Hedges JH, Curtis CE (2012) Prioritized maps of space in human frontoparietal cortex. J Neurosci 32:1738217390. CrossRef Medline

Kandel ER (2013) Principles of neural science, Ed 5. New York: McGraw-Hill.

Krappmann P, Everling S (1998) Spatial accuracy of primary and secondary memory-guided saccades in schizophrenic patients. Schizophr Res 30: 183-185. CrossRef Medline

Lebedev MA, Messinger A, Kralik JD, Wise SP (2004) Representation of attended versus remembered locations in prefrontal cortex. PLoS Biol 2:e365. CrossRef Medline

Luna B, Garver KE, Urban TA, Lazar NA, Sweeney JA (2004) Maturation of cognitive processes from late childhood to adulthood. Child Dev 75: 1357-1372. CrossRef Medline

Medendorp WP, Goltz HC, Vilis T (2006) Directional selectivity of BOLD activity in human posterior parietal cortex for memory-guided doublestep saccades. J Neurophysiol 95:1645-1655. CrossRef Medline

Meienberg O, Zangemeister WH, Rosenberg M, Hoyt WF, Stark L (1981) Saccadic eye movement strategies in patients with homonymous hemianopia. Ann Neurol 9:537-544. CrossRef Medline

Milner B (1963) Effects of different brain lesions on card sorting: role of frontal lobes. Arch Neurol 9:90. CrossRef

Paré M, Wurtz RH (1997) Monkey posterior parietal cortex neurons antidromically activated from superior colliculus. J Neurophysiol 78: 3493-3497. Medline

Park S, Holzman PS (1992) Schizophrenics show spatial working memory deficits. Arch Gen Psychiatry 49:975-982. CrossRef Medline

Pasternak T, Lui LL, Spinelli PM (2015) Unilateral prefrontal lesions impair memory-guided comparisons of contralateral visual motion. J Neurosci 35:7095-7105. CrossRef Medline

Pierrot-Deseilligny C, Rivaud S, Gaymard B, Agid Y (1991) Cortical control of memory-guided saccades in man. Exp Brain Res 83:607-617. Medline

Ploner CJ, Rivaud-Péchoux S, Gaymard BM, Agid Y, Pierrot-Deseilligny C (1999) Errors of memory-guided saccades in humans with lesions of the frontal eye field and the dorsolateral prefrontal cortex. J Neurophysiol 82:1086-1090. Medline

Purves D (2012) Neuroscience, Ed 5. Sunderland, MA: Sinauer.

Rath-Wilson K, Guitton D (2015) Oculomotor control after hemidecortication: a single hemisphere encodes corollary discharges for bilateral saccades. Cortex 63:232-249. CrossRef Medline

Saber GT, Pestilli F, Curtis CE (2015) Saccade planning evokes topographically specific activity in the dorsal and ventral streams. J Neurosci 35 : 245-252. CrossRef Medline

Schluppeck D, Curtis CE, Glimcher PW, Heeger DJ (2006) Sustained activity in topographic areas of human posterior parietal cortex during memory-guided saccades. J Neurosci 26:5098-5108. CrossRef Medline

Sheremata SL, Bettencourt KC, Somers DC (2010) Hemispheric asymmetry in visuotopic posterior parietal cortex emerges with visual short-term memory load. J Neurosci 30:12581-12588. CrossRef Medline

Sommer MA, Tehovnik EJ (1997) Reversible inactivation of macaque frontal eye field. Exp Brain Res 116:229-249. CrossRef Medline

Sommer MA, Wurtz RH (2001) Frontal eye field sends delay activity related 
to movement, memory, and vision to the superior colliculus. J Neurophysiol 85:1673-1685. Medline

Sprague TC, Ester EF, Serences JT (2014) Reconstructions of information in visual spatial working memory degrade with memory load. Curr Biol 24:2174-2180. CrossRef Medline

Squire LR (2013) Fundamental neuroscience, Ed 4. Amsterdam: Elsevier/Academic.

Sreenivasan KK, Curtis CE, D'Esposito M (2014) Revisiting the role of persistent neural activity during working memory. Trends Cogn Sci 18: 82-89. CrossRef Medline

Srimal R, Curtis CE (2008) Persistent neural activity during the maintenance of spatial position in working memory. Neuroimage 39:455-468. CrossRef Medline

Srimal R, Curtis CE (2010) Secondary adaptation of memory-guided saccades. Exp Brain Res 206:35-46. CrossRef Medline

Stuss DT, Levine B, Alexander MP, Hong J, Palumbo C, Hamer L, Murphy KJ,
Izukawa D (2000) Wisconsin Card Sorting Test performance in patients with focal frontal and posterior brain damage: effects of lesion location and test structure on separable cognitive processes. Neuropsychologia 38:388-402. CrossRef Medline

Sweeney JA, Kmiec JA, Kupfer DJ (2000) Neuropsychologic impairments in bipolar and unipolar mood disorders on the CANTAB neurocognitive battery. Biol Psychiatry 48:674-684. CrossRef Medline

Tsujimoto S, Postle BR (2012) The prefrontal cortex and oculomotor delayed response: a reconsideration of the "mnemonic scotoma." J Cogn Neurosci 24:627-635. CrossRef

Voytek B, Davis M, Yago E, Barceló F, Vogel EK, Knight RT (2010) Dynamic neuroplasticity after human prefrontal cortex damage. Neuron 68: 401-408. CrossRef Medline

Wechsler D (2008) WAIS-IV Wechsler adult intelligence scale. Ed 4. San Antonio, TX: Psychological Corporation. 